\title{
Factors associated with caregiver burden among pharmacotherapy-treated children/adolescents with ADHD in the Caregiver Perspective on Pediatric ADHD survey in Europe
}

\author{
This article was published in the following Dove Press journal: \\ Neuropsychiatric Disease and Treatment \\ 7 February 2017 \\ Number of times this article has been viewed
}

\author{
Moshe Fridman' \\ Tobias Banaschewski \\ Vanja Sikirica ${ }^{3}$ \\ Javier Quintero ${ }^{4}$ \\ $M$ Haim Erder ${ }^{3}$ \\ Kristina S Chen ${ }^{5}$ \\ 'AMF Consulting, Inc., Los Angeles, \\ CA, USA; ${ }^{2}$ Department of Child \\ and Adolescent Psychiatry and \\ Psychotherapy, Central Institute \\ of Mental Health, Medical Faculty \\ Mannheim of the University of \\ Heidelberg, Mannheim, Germany; \\ ${ }^{3}$ Global Health Economics Outcomes \\ Research and Epidemiology, Shire, \\ Wayne, PA, USA; ${ }^{4}$ Psychiatry \\ Department, Hospital Universitario \\ Infanta Leonor, Complutense \\ University, Madrid, Spain; ${ }^{5}$ Global \\ Health Economics Outcomes \\ Research and Epidemiology, Shire, \\ Lexington, MA, USA
}

Background: Burden on caregivers of children/adolescents with attention-deficit/hyperactivity disorder (ADHD) is multidimensional, but incompletely understood.

Objective: To analyze caregiver burden across the concepts of work, social/family life, and parental worry/stress, in relation to selected contributing factors.

Methods: The online Caregiver Perspective on Pediatric ADHD survey was fielded in ten European countries. Analysis included children/adolescents (6-17 years) who were receiving/ had received ADHD pharmacotherapy in the previous 6 months. Caregivers recorded their child's/adolescent's symptoms "on"/“off" medication (ie, when the caregiver reported that the child/adolescent forgot/chose not to take medication, before the onset of medication effect, or medication worn off). Effects of ADHD severity, comorbidities, and medication adherence on each burden outcome were assessed (multiple regression models).

Results: In total, 2,326 caregivers were included (children/adolescents' mean age: 11.5 years, $80 \%$ male). Caregivers reported missed/altered work, avoiding social activity, increased parental worry/stress, and strain on family life, despite using ADHD pharmacotherapy. Child/adolescent comorbidities and ADHD severity were significantly related to all burden concepts measured; the strongest comorbidity associations were with altered work (odds ratios [ORs] $=1.68[95 \%$ confidence interval $\{\mathrm{CI}\} 1.33,2.12], 1.87$ [1.37, 2.54], 3.47 [2.51, 4.78] for 1, 2, 3+ comorbidities, respectively) and planning the day around the child/adolescent (OR $=1.42$ [95\% CI 1.17, $1.72], 1.73$ [1.33, 2.15], 2.65 [1.99, 3.53]); the strongest severity associations were: quitting a job $(\mathrm{OR}=1.41[95 \% \mathrm{CI} 1.26,1.59])$ and planning a day around the child/adolescent $(\mathrm{OR}=1.26$ [95\% CI 1.20, 1.32]). Increased medication adherence was most associated with reducing the caregiver burden for altered work ( $\mathrm{OR}=0.57$ [95\% CI $0.45,0.72]$ ), worrying about how they are being perceived as a parent $(\mathrm{OR}=0.68[0.56,0.83])$, and avoiding social activity $(\mathrm{OR}=0.56$ $[0.45,0.68])$, but not family or stress burden.

Conclusion: Burdens related to work, social activity, family life, and parental worry/stress were experienced by the caregivers of children/adolescents with ADHD, despite using ADHD pharmacotherapy. Better understanding of clinical/treatment characteristics most associated with the components of caregiver burden may help improve ADHD management and may ease caregiver burden.

Keywords: attention-deficit/hyperactivity disorder, treatment, caregivers, burden of illness

\section{Introduction}

Attention-deficit/hyperactivity disorder (ADHD) is a neurobehavioral disorder characterized by inattention, impulsivity, and hyperactivity. ${ }^{1,2}$ It is one of the most
Correspondence: Moshe Fridman Avenue, Los Angeles, CA 90036, USA

$\mathrm{Tel}+\mathrm{I} 3238576618$

Fax + I 3238576656

Email fmoshe@amf-consulting.com 
common psychiatric disorders of childhood and affects $3 \%-5 \%$ of children and adolescents worldwide. ${ }^{3-5}$ Multidisciplinary management involving educational, psychological, and behavioral interventions and pharmacologic treatment is recommended by most European guidelines. ${ }^{1,6-10}$ Pharmacologic and nonpharmacologic interventions have been shown to reduce ADHD symptoms; however, some individuals continue to experience symptoms or functional impairment that negatively affect their own and their family's lives. ${ }^{11,12}$

Multiple studies have documented the negative impact that ADHD has on the daily lives of parents or caregivers, causing difficulties at home and straining family relationships. ${ }^{13-16}$ A large Danish study ${ }^{17}$ concluded that having a child or adolescent with ADHD reduces parental socioeconomic status by lowering their labor supply (the number of working hours people are willing and able to supply) and earnings, and reduces their relationship stability. In a recent survey, caregivers interviewed in eight European Union countries reported that their child's ADHD negatively affected their social life and strained their relationships. ${ }^{18}$ Other studies have found increased parenting stress ${ }^{19}$ and increased rates of mood and anxiety disorders ${ }^{20,21}$ among parents and/or siblings of children with ADHD, as well as a negative impact of ADHD behaviors on family life. ${ }^{22}$

The web-based cross-sectional Caregiver Perspective on Pediatric ADHD (CAPPA) survey was designed to evaluate the caregiver burden associated with ADHD and its treatment, and identify the unmet needs in the management of this condition. ${ }^{23}$ Caregiver burden is a multidimensional construct that includes mental distress, economic, and social/family components; however, the relationship between each of these components of caregiver burden and the contributing factors is not fully understood. The objective of this study was to analyze CAPPA survey data for caregiver burden relating to work, social and family life, and parental worry/stress, and to assess the effect of the severity of ADHD, comorbidities, and adherence to medication.

\section{Methods}

\section{Study design}

The CAPPA survey of caregivers of children/adolescents diagnosed with ADHD was conducted online between November 2012 and April 2013 in ten European countries (Denmark, Finland, France, Germany, Italy, the Netherlands, Norway, Spain, Sweden, and the UK).

\section{The survey}

The survey methodology is reported in detail elsewhere, together with a descriptive summary of the data (including sociodemographic and clinical characteristics) reported by country. ${ }^{23}$ The survey included questions on sociodemographic characteristics of the caregivers and their child/ adolescent with ADHD. Caregivers were asked to report on the child's/adolescent's ADHD when "on medication" and "off medication". Time off medication was defined as the following (as reported by the caregiver): the child/ adolescent forgot to take medication; the child/adolescent intentionally chose not to take medication (eg, holidays or weekends); in the morning before the medication took effect; or in the afternoon or evening when the medication had worn off. These questions were included to evaluate the influence of ADHD treatment on the child/adolescent (in terms of symptoms [using the ADHD-Rating Scale-IV] and academic, family, and social functioning) and the impact of the child's/adolescent's ADHD on their caregiver (in terms of time, emotions, family, social activities, and work). Only caregivers who reported that their child/adolescent had been off medication for any time in the past 6 months answered the off medication questions. ${ }^{23}$

\section{Ethical review}

The study was reviewed and approved by a central institutional review board (MaGil IRB), and was performed in accordance with the ethical standards of the Declaration of Helsinki. Caregivers were asked to provide written informed consent before completing the survey.

\section{Participants}

Full inclusion/exclusion criteria are reported in detail elsewhere. ${ }^{23}$ Briefly, participants were eligible for inclusion if they were a parent or legal guardian of a child/adolescent aged 6-17 years diagnosed with ADHD at least 6 months before study enrollment and with no severe intellectual disability (cognitive impairment with an intelligence quotient $<70$ ). Only one caregiver per child could participate and the child had to reside with the caregiver for at least $50 \%$ of the time during the 6 months immediately before the survey. This analysis includes children/adolescents who, at the time of the survey, were currently receiving, or had received in the previous 6 months, ADHD pharmacologic treatment, and had experienced periods where they were reported to be off medication. 


\section{Independent variables}

The associations between the following key independent variables and caregiver burden were examined: number and types of comorbidities, ADHD subtypes and severity of symptoms, and adherence to medication. Other child/adolescent and caregiver characteristics that could have a confounding effect on these relationships were controlled for as covariates in regression models. These included country, child's/ adolescent's age and sex, family ADHD status (parents have ADHD, siblings have ADHD, other family members have ADHD, no family member has ADHD), caregiver's relationship to child (mother, father, other), number of children in the caregiver's household $(1,2,3+)$, caregiver's marital status (single, married, divorced, widowed), caregiver's work status (employed, unemployed - looking, unemployed - not looking, other), and caregiver's education level (none, General Certificate of Secondary Education/O-level or equivalent, A-level or equivalent, university, postgraduate).

\section{Comorbidities}

Comorbid conditions were selected from a predefined list based on those previously identified as common in an ADHD claims database study ${ }^{24}$ (a list of reported comorbidities can be found in Flood et $\mathrm{al}^{23}$ ). To represent baseline comorbidity, the total number of comorbidities was scored as 0 , 1,2 , or $3+$. In addition, the comorbidities were classified according to groupings including: 1) learning difficulties, motor-coordination disorder, speech/language disorder; 2) conduct disorder (CD), oppositional defiant disorder (ODD); 3) anxiety; and 4) autism, Asperger syndrome.

\section{ADHD subtypes and severity}

The influence of ADHD treatment on the child's/adolescent's symptoms was assessed using the ADHD-Rating Scale-IV. The ADHD-Rating Scale-IV total score while off medication was used as a proxy for baseline ADHD severity and to determine the ADHD subtype according to the criteria of the Diagnostic and Statistical Manual of Mental Disorders, 4th Edition. The three standard ADHD subtypes of inattention, hyperactivity/impulsivity, and combined were assigned to each child/adolescent, and those who did not meet any subtype criteria were grouped as "unclassified".

\section{Treatment adherence}

Medication adherence was examined as a key factor of caregiver burden. Children/adolescents were classified as adherent if their caregivers reported "daily/always" prescriptions with an adherence of $\geq 80 \%$ on weekdays and $\geq 50 \%$ on average for weekends/holidays. In cases where the physician's recommendation for dosing was "as needed", caregivers were not asked about the percentage adherence. If the "as needed" recommendation was given for both weekdays and weekends/holidays, such patients were excluded from analyses involving adherence. However, if the "as needed" dosing recommendation, or a recommendation of "never", was given only for weekends/holidays, adherence was calculated based on weekdays only.

All children/adolescents included in this study were being treated with medications in an observational community setting. As we did not intend to examine the differences in caregiver burden across pharmacotherapies, treatment was considered to be "standard" and, therefore, an approximate constant that did not require controlling for this analysis.

\section{Measures of caregiver burden}

Caregivers were questioned about various aspects of their work, social life, family life, and worry/stress in order to assess the burden of having a child/adolescent with ADHD. Responses were recorded as categorical variables unless stated otherwise.

\section{Work}

- Have you had to change your job, cut back your work hours, work schedule, or quit work altogether due to your child's ADHD?

(Response options were "yes, had to change job", "yes, had to change work shift", "yes, had to cut back hours", "yes, had to quit working", or "no".)

- In the past 4 weeks, how many total hours of work did you miss due to your child's ADHD?

(Responses were analyzed on a continuous scale.)

\section{Social life}

Over the past 6 months:

- How often did you plan your day around your child?

- How often did you avoid social activities when with your child?

- How often did you worry about other people's perceptions of you as a parent?

(Response options were "almost all the time $[90 \%$ or higher]", "most of the time [75\%]", "some of the time $[50 \%]$ ", "a little of the time [25\%]", or "never [0\%]".) 
Family life

Over the past 6 months:

- How much strain did your child's ADHD put on your relationship with your partner?

- How much strain did your child's ADHD put on your relationship with your other children?

(Response options were "a tremendous amount of strain", "a lot of strain", "a moderate amount of strain", "a little strain", "no strain".)

\section{Worry/stress}

Over the past 6 months, how much time did you spend worrying or stressing about your child?

(Response options were "a tremendous amount of time", "a lot of time", "a moderate amount of time", "a little time", "no time".)

\section{Analyses}

The effects of ADHD severity, the presence of comorbidities, ADHD subtype, and medication adherence on each of the caregiver burden outcomes were assessed using multiple regression models. For each outcome, we report 1) the independent effects for each of these key factors and 2) the mutually adjusted effects for simultaneously significant key factors (when included together in the same multiple regression model). The independent effects measured the burden attributed to each of the key factors alone, while the mutually adjusted effects measured their simultaneous contribution. Both types of models were adjusted for all potential confounding effects.

"Total hours of work missed" data were fitted using ordinary least-squares multiple regression. Data for all other polytomous outcomes (with three or four ordinal levels) were fitted using partial proportional-odds multiple regression models. The partial proportional-odds multiple regression model is a hybrid of the proportional-odds model and the generalized logit model ${ }^{25}$ that allows for model predictors to have either an equal or unequal effect across the ordinal levels of the outcome, based on the significance of score tests for the proportional-odds assumption for each of the model's predictors. ${ }^{26}$ If the proportional-odds assumption fails, odds ratios (ORs) are calculated and presented for all levels of the outcome compared with the reference; if the assumption does not fail, a single OR is calculated and presented for that variable.

Pooled (pan-European) and country-specific descriptive statistics are reported for each of the caregiver burden outcomes and for the independent variables of interest and confounders. Differences across countries were tested with chi-square tests and analysis of variance $F$-tests for categori$\mathrm{cal}$ and continuous variables, respectively. The associations among the eight caregiver burden outcomes were examined using Pearson correlations. Ranges of correlations within and between the four outcome groups (concepts) are reported. Correlations among key factors were also evaluated to examine collinearity. For all models, adjusted estimates of slopes (for the linear model) and ORs (for logistic models) are reported along with their $95 \%$ confidence intervals (CIs) and $P$-values. For key factor estimates involving more than one parameter, the overall Wald chi-square $P$-value is also reported. For the continuous ADHD severity independent variable, an increase in severity by half a standard deviation (SD) for the ADHD-Rating Scale-IV total score (as a measure of clinical meaningfulness) was used to calculate ORs. Measures of overall fit (coefficient of determination $R^{2}$ for linear models and c-statistic for logistic models) are reported for the multiple regressions that simultaneously include multiple key factors. All statistical tests were two-sided, with significance predetermined as $P<0.05$. There was no adjustment for multiple testing.

\section{Results}

\section{Patient population}

A total of 2,326 caregivers were included in this analysis (Table 1). The mean (SD) age of the children/adolescents was 11.5 (3.1) years and $80 \%$ were male. Two-thirds of the caregivers were mothers and $73 \%$ were employed. Significant variations in characteristics were observed between the countries.

\section{Selected independent variables}

Half (51\%) of the caregivers reported no conditions comorbid to ADHD in the child/adolescent; $27 \%, 12 \%$, and $10 \%$ reported 1, 2, and 3+ comorbidity classes present, respectively. The mean (SD) ADHD severity score was 34.6 (12.4), with a range of 26.2-38.9. ADHD subtype classification was $18 \%$ inattentive, $5 \%$ hyperactivity/impulsivity, and $50 \%$ combined subtype; the remaining $27 \%$ did not meet any ADHD-Rating Scale-IV subtype criterion (Table 1). Adherence (defined as "daily/always" prescriptions with adherence of $\geq 80 \%$ on weekdays and $\geq 50 \%$ on average for weekends/holidays to medication) was reported by $75 \%$ of caregivers (Table 1). Significant variation in these variables was observed between the countries, with the exception of some of the rare comorbid conditions.

\section{Caregiver burden}

Significant between-country variability in caregiver burden outcomes was observed (Table 2). 


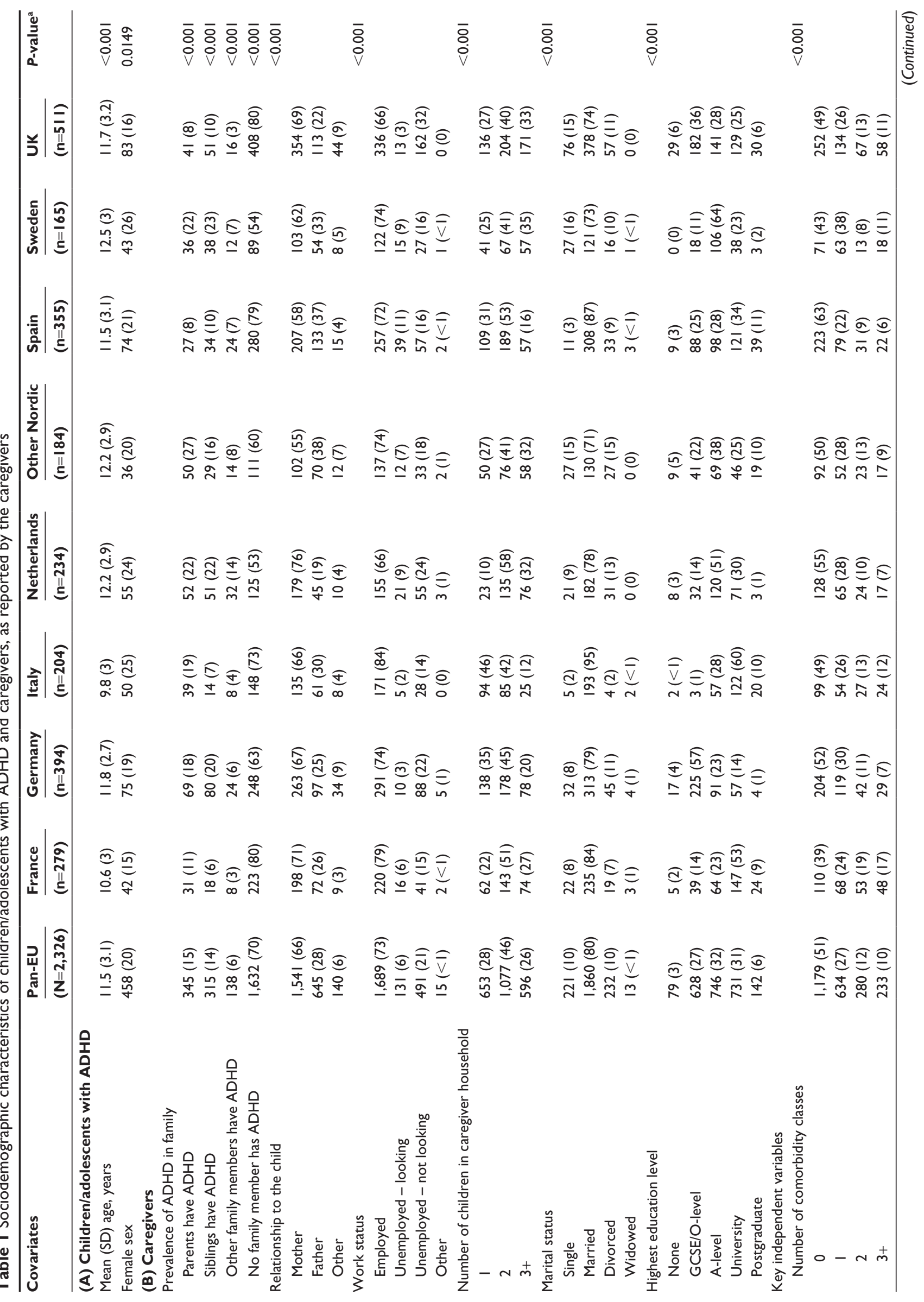




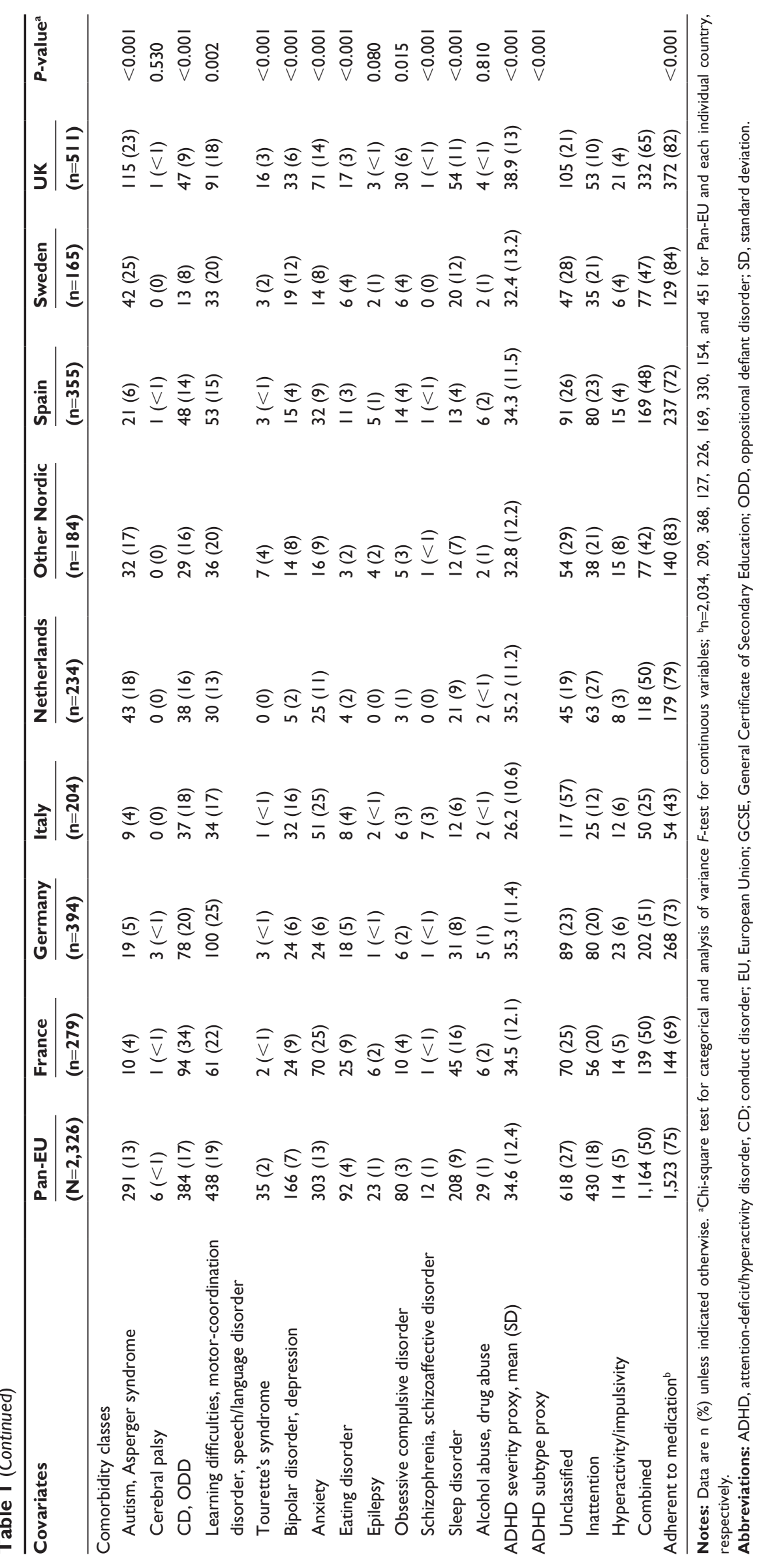




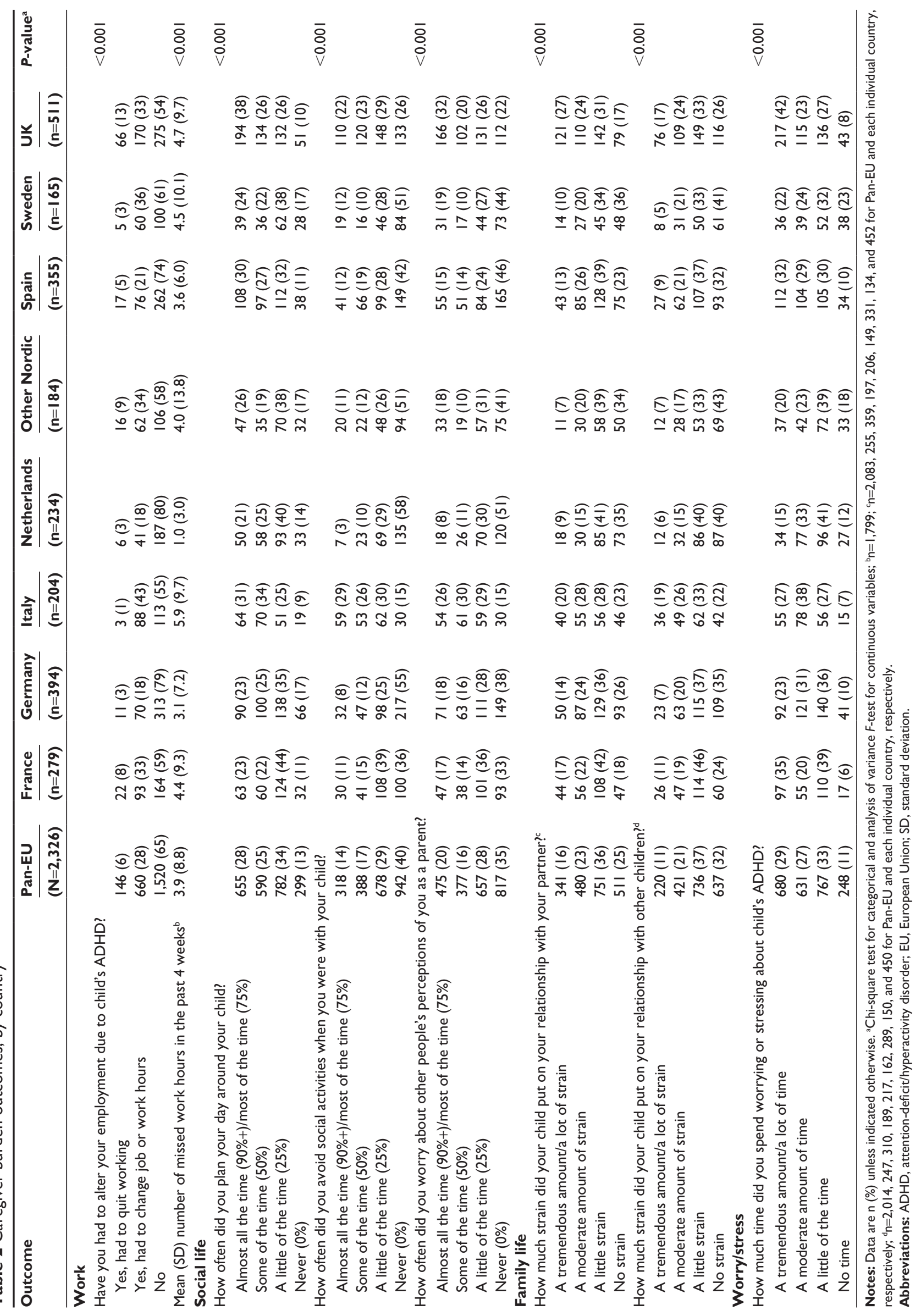


Work

Overall, $6 \%$ of caregivers reported having to quit their job (range $1 \%-13 \%$ ) and $28 \%$ had to change job or modify their work hours (range 18\%-43\%). The mean (SD) number of work hours missed during the past 4 weeks was 3.9 (8.8) hours (range 1.0-5.9 hours).

\section{Social life}

More than a quarter (28\%; range 21\%-38\%) of caregivers reported planning their day around the child almost all/ most of the time, and 14\% (range 3\%-29\%) avoided social activities when with their child almost all/most of the time. Overall, 20\% (range 8\%-32\%) of caregivers reported worrying about other people's perception of them almost all/ most of the time.

\section{Family life}

A tremendous amount/a lot of strain in the relationship with their partner and their other children was reported by $16 \%$ (range 7\%-27\%) and 11\% (range 5\%-19\%) of caregivers, respectively.

\section{Worry/stress}

Overall, 29\% (range 15\%-42\%) of caregivers reported a tremendous amount/a lot of time spent worrying or stressing about their child's ADHD.

\section{Correlations among caregiver burden outcomes}

"Number of work hours missed" had the lowest correlational absolute values; the correlation with altered work status was -0.24 , while correlations with the other outcomes ranged from -0.13 to -0.18 . Altered work status correlations with social, family, and worry/stress caregiver burden ranged from 0.20 to 0.25 . Correlations within the three social life burden questions ranged from 0.44 to 0.59 ; correlations between the social life burden questions and the family life burden questions ranged from 0.37 to 0.44 ; those between the social life burden questions and the worry/stress question ranged from 0.38 to 0.46 . Correlation within the two family life burden questions was 0.60 , and the correlations between these two questions and the worry/stress question ranged from 0.43 to 0.52 . All correlations were statistically significant $(P<0.001)$ (data not shown).

\section{Key independent variable correlations}

Presence of the six most common individual comorbidity classes was closely associated with the number of comorbidity classes $\left(R^{2}=0.85\right)$; the presence of these individual comorbidity classes was, therefore, excluded from simultaneous multiple regression models. Similarly, ADHD subtype was highly correlated with ADHD severity (Spearman correlation, $r=0.86$ ); therefore, only ADHD severity was retained in simultaneous models.

\section{Multivariate analysis}

\section{Independently adjusted effects}

For most outcomes across the four burden concepts (work, social/family life, worry/stress), ORs were highest for children/adolescents with combined ADHD subtype versus other subtypes (Tables S1-S4), indicating greater caregiver burden. In general, the comorbidity classes associated with the highest caregiver burden on work outcomes were autism/ Asperger syndrome and CD/ODD (Table S1).

\section{Mutually adjusted effects}

Effect sizes were lower when estimated mutually, compared with the same effects estimated independently. For most outcomes, we estimated a significant increase in caregiver burden with an increase in comorbidities and ADHD severity and with a decrease in medication adherence. The predictive power of the logistic regression models, as measured by the c-statistic, ranged from 0.648 to 0.730 , and the variance in missed work hours explained was $R^{2}=0.168$.

\section{Work}

The ORs that a caregiver needed to alter employment when a child had 1, 2, and $3+$ comorbidity classes present were 1.68-fold (95\% CI 1.33, 2.12), 1.87-fold (95\% CI 1.37, 2.54), and 3.47 -fold $(95 \%$ CI 2.51, 4.78) higher than when a child had no comorbidities, respectively (all $P<0.001$; Table 3 ). For children with more versus less ADHD, the odds that a caregiver quit their job or changed their job/hours were 1.41fold $(95 \%$ CI 1.26, 1.59; $P<0.001)$ and 1.08 -fold $(95 \%$ CI $1.02,1.15 ; P=0.005)$ higher, respectively. Caregivers whose child/adolescent was adherent to medication were about half as likely to need to alter their employment versus those whose child/adolescent was not adherent (OR $=0.57 ; 95 \%$ CI 0.45 , 0.72; $P<0.001$; Table 3).

The predicted number of missed work hours reported by the caregivers during the previous 4 weeks was 1.56 (95\% CI 0.48, 2.64; $P=0.005), 1.24$ (95\% CI -0.30, 2.77; $P=0.115)$, and 3.34 (95\% CI 1.72, 4.96; $P<0.001)$ for those with a child/adolescent with 1,2 , and $3+$ comorbidity classes present relative to no comorbidity, respectively (Table 3). For children/adolescents with more versus less severe ADHD, 


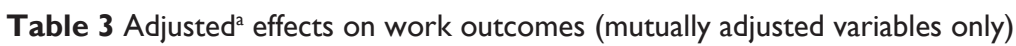

Measure of caregiver burden: (A) Have you had to alter your employment due to your child's ADHD?

I. Yes - quit job; 2. Yes - changed job or shift/cut hours; 3. No (ref)

\begin{tabular}{|c|c|c|}
\hline \multirow[t]{2}{*}{ Key independent variable } & \multicolumn{2}{|c|}{ Mutually adjusted effects ${ }^{c}(c=0.730)$} \\
\hline & OR (95\% CI) & $P$-value \\
\hline \multicolumn{2}{|l|}{ Number of comorbidity classes (ref $=$ none) } & $<0.001$ \\
\hline I & $1.68(1.33,2.12)$ & $<0.001$ \\
\hline 2 & $\mathrm{I} .87(1.37,2.54)$ & $<0.001$ \\
\hline $3+$ & $3.47(2.5 \mathrm{I}, 4.78)$ & $<0.001$ \\
\hline \multicolumn{2}{|l|}{ ADHD severity proxy (unit $=6.2)^{d}$} & $<0.001$ \\
\hline Yes - quit job & $1.41(1.26,1.59)$ & $<0.001$ \\
\hline Yes - changed job or shift/cut hours & $1.08(1.02,1.15)$ & 0.005 \\
\hline Adherent to medication ${ }^{c}(r e f=$ nonadherent $)$ & $0.57(0.45,0.72)$ & $<0.001$ \\
\hline \multicolumn{3}{|c|}{ Measure of caregiver burden: (B) Number of missed work hours in the past 4 weeks ${ }^{e}$} \\
\hline & \multicolumn{2}{|c|}{ Mutually adjusted effects $\left(R^{2}=0.168\right)$} \\
\hline & Slope $(95 \% \mathrm{Cl})$ & P-value \\
\hline \multicolumn{2}{|l|}{ Number of comorbidity classes ( $r e f=$ none $)$} & $<0.001$ \\
\hline I & $1.56(0.48,2.64)$ & 0.005 \\
\hline 2 & $1.24(-0.30,2.77)$ & 0.115 \\
\hline $3+$ & $3.34(1.72,4.96)$ & $<0.001$ \\
\hline ADHD severity proxy (unit $=6.2^{\mathrm{d}}$ ) & $0.26(0.0 \mathrm{I}, 0.5 \mathrm{I})$ & 0.045 \\
\hline Adherent to medication $($ ref $=$ nonadherent $)$ & $-1.84(-2.93,-0.75)$ & 0.001 \\
\hline
\end{tabular}

Notes: aControlled for country, age, sex, ADHD in family status (parents/siblings/other family/none), caregiver's relationship, caregiver's number of children, caregiver's responsibility, caregiver's marital status, caregiver's work status (excluded in Model B for work hours lost), and caregiver's education level; bdata were fitted using proportionalodds multiple regression models. If the proportional-odds assumption fails, ORs are calculated and presented for all levels of the outcome compared with the ref; if the assumption

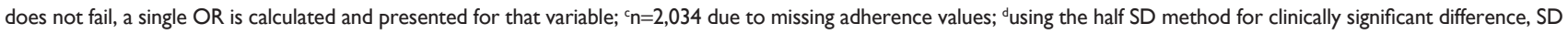
is I2.4=6.2 units; 'data were fitted using ordinary least-squares multiple regression; ${ }^{f} n=I, 543$ due to missing adherence values and missing values for unemployed respondents. Abbreviations: ADHD, attention-deficit/hyperactivity disorder; c, c-statistic; Cl, confidence interval; OR, odds ratio; $R^{2}$, coefficient of determination; ref, reference; SD, standard deviation.

the predicted number of missed working hours for the caregiver was $0.26(95 \%$ CI $0.01,0.51 ; P=0.045)$. Caregivers with adherent children/adolescents were predicted to have gained an average of 1.84 hours over 4 weeks ( $95 \%$ CI $-2.93,-0.75$; $P=0.001$; Table 3).

\section{Social life}

The same general trends applied to social life outcomes (Table 4). However, the effect of medication adherence on planning the day around the child/adolescent $(\mathrm{OR}=0.87$; $95 \%$ CI $0.71,1.06 ; P=0.179$ ) was not significant. The effect of adherence was significant, but weaker, for participation in social events $(\mathrm{OR}=0.56 ; 95 \% \mathrm{CI} 0.45,0.68 ; P<0.001)$ and worry of other people's perceptions ( $\mathrm{OR}=0.68 ; 95 \% \mathrm{CI}$ $0.56,0.83 ; P<0.001)$.

\section{Family life}

Again, the same general trends for estimates applied to the family life outcomes (Table 5). However, the effect of medication adherence on strain on relationship with partner $(\mathrm{OR}=0.88 ; 95 \% \mathrm{CI} 0.72,1.08 ; P=0.231)$ was not significant .
The effect of adherence was significant, but weaker, for strain on relationship with other children $(\mathrm{OR}=0.75 ; 95 \%$ CI 0.60 , $0.93 ; P=0.008$ ).

\section{Worry/stress}

Most of the same general trends for estimates applied to the worry/stress outcome (Table 6). However, the effect of medication adherence $(\mathrm{OR}=1.02 ; 95 \%$ CI $0.84,1.24 ; P=0.857)$ was not significant.

\section{Discussion}

To our knowledge, this is the largest community-based study to date on the burden on caregivers of children/adolescents with ADHD. We examined eight different burden outcomes that corresponded to four different concepts and considered the differences in the simultaneous effects of comorbidity, ADHD severity, and medication adherence. In this web-based survey, caregivers reported substantial burden related to work, social activity, family life, and parental stress, despite the use of pharmacotherapy for ADHD. These findings are broadly in line with previous findings. ${ }^{17,27-30}$ 
Table 4 Adjusted $^{\mathrm{a}}$ effects on social life outcomes (mutually adjusted variables only)

Measure of caregiver burden: (A) Over the past 6 months, how often did you plan your day around your child? I. Almost all the time $(90 \%+) /$ most of the time (75\%); 2 . Some of the time (50\%); 3. A little of the time (25\%); 4 . Never (ref)

\begin{tabular}{|c|c|c|}
\hline \multirow[t]{2}{*}{ Key independent variable } & \multicolumn{2}{|c|}{ Mutually adjusted effects ${ }^{b}(c=0.686)$} \\
\hline & OR $(95 \% \mathrm{Cl})$ & $P$-value \\
\hline Number of comorbidity classes ( $r e f=$ none $)$ & & $<0.001$ \\
\hline I & $1.42(1.17,1.72)$ & $<0.001$ \\
\hline 2 & $1.73(1.33,2.15)$ & $<0.001$ \\
\hline $3+$ & $2.65(1.99,3.53)$ & $<0.001$ \\
\hline ADHD severity proxy (unit $=6.2^{c}$ ) & $1.26(1.20,1.32)$ & $<0.001$ \\
\hline Adherent to medication $(\mathrm{ref}=$ nonadherent $)$ & $0.87(0.71,1.06)$ & 0.179 \\
\hline
\end{tabular}

Measure of caregiver burden: (B) Over the past 6 months, how often did you avoid social activities when with your child? I. Almost all the time $(90 \%+) /$ most of the time (75\%); 2 . Some of the time (50\%); 3. A little of the time (25\%); 4 . Never (ref)

\begin{tabular}{|c|c|c|}
\hline & \multicolumn{2}{|c|}{ Mutually adjusted effects ${ }^{b}(c=0.705)$} \\
\hline & OR $(95 \% \mathrm{CI})$ & $P$-value \\
\hline Number of comorbidity classes (ref $=$ none $)$ & & $<0.001$ \\
\hline 1 & $1.32(1.08,1.61)$ & 0.006 \\
\hline 2 & $1.63(1.24,2.15)$ & $<0.001$ \\
\hline $3+$ & $2.53(1.90,3.35)$ & $<0.001$ \\
\hline ADHD severity proxy (unit $=6.2^{c}$ ) & & 0.001 \\
\hline Almost all the time $(90 \%+) /$ most of the time $(75 \%)$ & $\mathrm{I} .04(0.97, \mathrm{I} .12)$ & 0.258 \\
\hline Some of the time $(50 \%)$ & $1.08(1.02,1.14)$ & 0.01 \\
\hline A little of the time $(25 \%)$ & $1.17(1.11,1.24)$ & $<0.001$ \\
\hline Adherent to medication ${ }^{\mathrm{b}}$ ( $\mathrm{ref}=$ nonadherent $)$ & $0.56(0.45,0.68)$ & $<0.001$ \\
\hline
\end{tabular}

Measure of caregiver burden: (C) Over the past 6 months, how often did you worry about other people's perceptions of you as a parent? I. Almost all the time $(90 \%+) /$ most of the time (75\%); 2 . Some of the time (50\%); 3. A little of the time (25\%); 4 . Never (ref)

\begin{tabular}{|c|c|c|}
\hline & \multicolumn{2}{|c|}{ Mutually adjusted effects ${ }^{b}(c=0.678)$} \\
\hline & OR (95\% Cl) & $P$-value \\
\hline Number of comorbidity classes ( $r e f=$ none $)$ & & 0.013 \\
\hline \multicolumn{3}{|l|}{ I } \\
\hline Almost all the time $(90 \%+) /$ most of the time $(75 \%)$ & $0.92(0.70,1.2 \mathrm{I})$ & 0.535 \\
\hline Some of the time $(50 \%)$ & $\mathrm{I} .07(0.85, \mathrm{I} .34)$ & 0.593 \\
\hline A little of the time $(25 \%)$ & $\mathrm{I} .05(0.84, \mathrm{I} .3 \mathrm{I})$ & 0.693 \\
\hline \multicolumn{3}{|l|}{2} \\
\hline Almost all the time $(90 \%+) /$ most of the time $(75 \%)$ & $1.34(0.95,1.88)$ & 0.094 \\
\hline Some of the time $(50 \%)$ & $1.17(0.86,1.60)$ & 0.319 \\
\hline A little of the time $(25 \%)$ & $1.26(0.92,1.73)$ & 0.155 \\
\hline \multicolumn{3}{|l|}{$3+$} \\
\hline Almost all the time $(90 \%+) /$ most of the time $(75 \%)$ & $1.55(I .08,2.2 I)$ & 0.017 \\
\hline Some of the time $(50 \%)$ & $2.59(1.87,3.59)$ & $<0.001$ \\
\hline A little of the time $(25 \%)$ & $2.25(1.55,3.26)$ & 0.043 \\
\hline ADHD severity proxy (unit $=6.2^{c}$ ) & $1.12(1.07,1.17)$ & $<0.001$ \\
\hline Adherent to medication ${ }^{\mathrm{b}}$ (ref $=$ nonadherent) & $0.68(0.56,0.83)$ & $<0.001$ \\
\hline
\end{tabular}

Notes: Data were fitted using proportional-odds multiple regression models. If the proportional-odds assumption fails, ORs are calculated and presented for all levels of the outcome compared with the ref; if the assumption does not fail, a single OR is calculated and presented for that variable. ${ }^{a}$ Controlled for country, age, sex, ADHD in family status (parents/siblings/other family/none), caregiver's relationship, caregiver's number of children, caregiver's responsibility, caregiver's marital status, caregiver's work status, and caregiver's education level; ${ }^{\mathrm{n}} \mathrm{n}=2,034$ due to missing adherence values; 'using the half SD method for clinically significant difference, SD is I2.4=6.2 units.

Abbreviations: ADHD, attention-deficit/hyperactivity disorder; c, c-statistic; Cl, confidence interval; OR, odds ratio; ref, reference; SD, standard deviation.

As noted previously in the CAPPA survey, ${ }^{23}$ the sociodemographic characteristics of the participating caregivers and children/adolescents with ADHD varied widely across European countries. The mean ages of children/ adolescents with ADHD ranged from 9.8 years in Italy to 12.5 years in Sweden.
All eight caregiver burden outcomes reported here were significantly and positively (except lost work hours, which is measured on a reversed scale) correlated with each other, suggesting families tend to experience more (or less) burden simultaneously across all types of burden. In general, slightly stronger correlations were observed among pairs of 


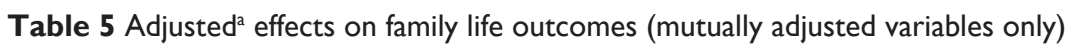

\begin{tabular}{|c|c|c|}
\hline \multicolumn{3}{|c|}{$\begin{array}{l}\text { Measure of caregiver burden: (A) Over the past } 6 \text { months, how much strain did your child's ADHD put on yo } \\
\text { your partner? } \\
\text { I. A tremendous amount/a lot of strain; 2. A moderate amount of strain; 3. A little strain; 4. No strain (ref) }\end{array}$} \\
\hline \multirow[t]{2}{*}{ Key independent variable } & \multicolumn{2}{|c|}{ Mutually adjusted effects ${ }^{b}(c=0.662)$} \\
\hline & OR $(95 \% \mathrm{Cl})$ & P-value \\
\hline Number of comorbidity classes (ref $=$ none) & & 0.001 \\
\hline 1 & $1.25(1.02,1.53)$ & 0.030 \\
\hline 2 & $1.62(1.22,2.15)$ & 0.001 \\
\hline $3+$ & $1.64(1.21,2.22)$ & 0.001 \\
\hline ADHD severity proxy (unit $=6.2^{c}$ ) & & $<0.001$ \\
\hline A tremendous amount/a lot of strain & $1.12(1.04,1,19)$ & 0.002 \\
\hline A moderate amount of strain & $1.10(1.04,1.19)$ & 0.001 \\
\hline A little strain & $1.18(1.11,1.25)$ & $<0.001$ \\
\hline Adherent to medication ( $r e f=$ nonadherent) & $0.88(0.72,1.08)$ & 0.231 \\
\hline
\end{tabular}

Measure of caregiver burden: (B) Over the past 6 months, how much strain did your child's ADHD put on your relationship with your other children?

I. A tremendous amount/a lot of strain; 2. A moderate amount of strain; 3. A little strain; 4. No strain (ref)

\begin{tabular}{|c|c|c|}
\hline & \multicolumn{2}{|c|}{ Mutually adjusted effects ${ }^{d}(c=0.648)$} \\
\hline & OR (95\% Cl) & $P$-value \\
\hline Number of comorbidity classes (ref $=$ none) & & $<0.001$ \\
\hline 1 & $1.16(0.94,1.42)$ & 0.169 \\
\hline 2 & $1.50(I .12,2.01)$ & 0.006 \\
\hline $3+$ & $1.75(1.29,2.38)$ & $<0.001$ \\
\hline ADHD severity proxy (unit $=6.2^{c}$ ) & $1.14(1.08,1.19)$ & $<0.001$ \\
\hline Adherent to medication ( $r$ ef $=$ nonadherent $)$ & $0.75(0.60,0.93)$ & 0.008 \\
\hline
\end{tabular}

Notes: Data were fitted using proportional-odds multiple regression models. If the proportional-odds assumption fails, ORs are calculated and presented for all levels of

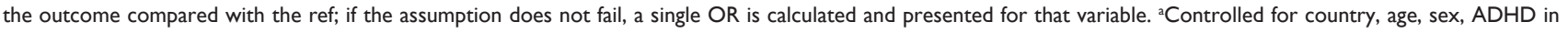
family status (parents/siblings/other family/none), caregiver's relationship, caregiver's number of children, caregiver's responsibility, caregiver's marital status, caregiver's work status, and caregiver's education level; ${ }^{b} \mathrm{n}=\mathrm{I}, 802$ for respondents without partners and due to missing adherence values; 'using the half SD method for clinically significant difference, SD is I $2.4=6.2$ units; ${ }^{\mathrm{d}} \mathrm{n}=1,756$ for respondents without other children and due to missing adherence values.

Abbreviations: ADHD, attention-deficit/hyperactivity disorder; c, c-statistic; $\mathrm{Cl}$, confidence interval; OR, odds ratio; ref, reference; SD, standard deviation.

outcomes within the same burden concepts compared with the correlations across the burden concepts, suggesting some commonality in the underlying factors related to outcomes within concepts. Confirming the results reported in previous studies, we observed a higher negative impact on caregiver burden for children with combined ADHD subtype (vs inattention only) ${ }^{31}$ and for those with comorbid autism/Asperger syndrome ${ }^{32}$ and $\mathrm{CD} / \mathrm{ODD}^{19,33}$ in the independently adjusted models.

As expected, the mutually adjusted effect estimates were generally slightly lower than their independently adjusted counterparts. However, for almost all variables, there were no discordant significant results and no substantial magnitude deviations, indicating relatively independent impacts of the number of comorbid classes, severity, and medication adherence on caregiver burden.

A higher number of comorbidity classes present and higher ADHD severity were significantly associated with greater caregiver burden for all outcomes. In addition, caregiver burden increased significantly with three or more comorbidity classes present (relative to each of the lower numbers of classes) in all but three burden outcomes examined (missed work hours, worry about perception as parent, strain in relationship with children). An increased number of comorbidity classes were significantly associated with a higher risk of employment changes, for 1,2 , or $3+$ comorbidity classes present compared with none. Similarly, strong associations were found between increasing frequency of comorbidities and increased risk of social burden related to planning the day around the child/adolescent. On average, caregivers of children with $3+$ comorbidity classes present were estimated to have more than double the average lost hours of work, compared with caregivers of children with one comorbidity class.

Higher ADHD severity was also found to be associated with increased caregiver burden in all burden concepts, consistent with prior findings. ${ }^{19}$ The strongest associations of severity were found with quitting a job and planning the day around the child/adolescent.

Examination of adherence ( $\geq 80 \%$ on weekdays and $\geq 50 \%$ on average for weekends/holidays) was of particular interest, 
Table 6 Adjusted $^{\text {a }}$ effects on worry/stress outcomes (mutually adjusted variables only)

\begin{tabular}{|c|c|c|}
\hline \multicolumn{3}{|c|}{$\begin{array}{l}\text { Measure of caregiver burden: (A) How much time did you } \\
\text { spend worrying or stressing about your child? } \\
\text { I. Almost all the time }(90 \%+) / \text { most of the time }(75 \%) ; 2 \text {. Some } \\
\text { of the time ( } 50 \%) ; 3 \text {. A little of the time }(25 \%) ; 4 \text {. Never (ref) }\end{array}$} \\
\hline \multirow[t]{2}{*}{ Key independent variable } & \multicolumn{2}{|c|}{$\begin{array}{l}\text { Mutually adjusted effects } \\
(c=0.666)\end{array}$} \\
\hline & OR $(95 \% \mathrm{Cl})$ & $P$-value \\
\hline $\begin{array}{l}\text { Number of comorbidity classes } \\
\text { (ref }=\text { none })\end{array}$ & & $<0.001$ \\
\hline 1 & $1.38(1.14,1.68)$ & $<0.001$ \\
\hline 2 & $1.60(1.22,2.09)$ & $<0.001$ \\
\hline $3+$ & $2.11(1.58,2.81)$ & $<0.001$ \\
\hline ADHD severity proxy (unit $=6.2^{c}$ ) & & $<0.001$ \\
\hline $\begin{array}{l}\text { Almost all the time }(90 \%+) / \\
\text { most of the time }(75 \%)\end{array}$ & $1.25(1.18,1.32)$ & $<0.001$ \\
\hline Some of the time $(50 \%)$ & $1.18(1.13,1.25)$ & $<0.001$ \\
\hline A little of the time $(25 \%)$ & $1.26(1.17,1.36)$ & $<0.001$ \\
\hline Adherent to medication ${ }^{\mathrm{b}}$ & $1.02(0.84,1.24)$ & 0.857 \\
\hline
\end{tabular}

(ref $=$ nonadherent $)$

Notes: Data were fitted using proportional-odds multiple regression models. If the proportional-odds assumption fails, ORs are calculated and presented for all levels of the outcome compared with the ref; if the assumption does not fail, a single OR is calculated and presented for that variable. ${ }^{2}$ Controlled for country, age, sex, ADHD in family status (parents/siblings/other family/none), caregiver's relationship, caregiver's number of children, caregiver's responsibility, caregiver's marital status, caregiver's work status, and caregiver's education level; ${ }^{b} n=2,034$ due to missing adherence values; 'using the half SD method for clinically significant difference, SD is I2.4=6.2 units. Abbreviations: ADHD, attention-deficit/hyperactivity disorder; c, c-statistic; $\mathrm{Cl}$, confidence interval; OR, odds ratio; ref, reference; SD, standard deviation.

as this is the only mutable factor that is to some degree within the caregiver's control. Examination of the effect of adherence on caregiver burden has not been reported in previous studies. Higher adherence to medication was associated with lower caregiver burden in five of the eight burden outcomes examined. The adherence effect was of similar magnitude for the strongest associations: avoiding social activities with the child/adolescent, altering job status, and worrying about other people's perceptions of them as a parent. Adherence also reduced the number of lost work hours to about half of the overall average work lost.

Our results show that caregiver burden in the family life and worry/stress concepts were significant, but the impact of the number of comorbidity classes present, ADHD severity, and adherence to medication was less pronounced for these concepts than for work and social life concepts - perhaps because problems with work and social life may be more difficult to compensate for. It is also important to note that the impact of different ADHD behaviors on family life varies according to factors such as the specific area of family life examined, as was demonstrated in a study of Spanish families. ${ }^{22}$

\section{Limitations}

This study has a number of limitations. First, we did not have a direct measure of baseline ADHD severity and our proxy measure is subject to bias as it was collected after the start of medication treatment. We did not have a true proxy of patients who were off medication, and bias could be introduced from their previous experience while on medication. These results should, therefore, be viewed in such a context, and not as the caregiver burden of patients truly naïve to ADHD medication whose responses may be different. Furthermore, clinically significant differences in this severity proxy were estimated only using a distribution-based method. In addition, although caregivers were asked about experiences during off medication times, no information about the duration of these periods was collected. As previously described, ${ }^{23}$ the data were collected from caregivers who completed a questionnaire consisting of multiple questions and, consequently, the clinical data relating to diagnosis, severity, and comorbidities have not been clinically validated. Findings from the CAPPA survey should, therefore, not be expected to be fully consistent with formal clinical assessments. As there are no ADHD-specific instruments for caregiver-reported burden and other concepts collected, creation of the questionnaire followed a rigorous concept elicitation ${ }^{18}$ and cognitive debriefing ${ }^{23}$ process, which is akin to those accepted by the Food and Drug Administration Clinical Outcome Assessment guidelines for registration of subjective questionnaire-based concepts such as these. Caregiver burden items on work, social life, family life, and worry/stress used were tested with caregivers through a cognitive debriefing study for applicability, comprehension, and interpretability by 52 caregivers. Although these concepts are internally valid and confirmed to be concepts of potential burden to caregivers, other psychometric properties of these items were not evaluated. The information reported by caregivers may be influenced by their understanding of ADHD, cultural beliefs, and other underlying characteristics, and the different ways by which clinical information is conveyed to caregivers across Europe. The impact of this limitation should be carefully considered as the focus of the analysis is centered on caregiver burdens, perceptions, and attitudes. Participants were recruited as a convenience sample through online patient panels, so these results may not be representative of those without Internet access and reporting bias may also be present.

\section{Conclusion}

This study found a substantial burden related to work, social activity, family life, and parental worry/stress reported 
by caregivers of children/adolescents with ADHD across Europe, despite the use of pharmacotherapy. Child/adolescent comorbidities and ADHD severity were significantly related to all burden concepts, but their association with caregivers' work and social-related outcomes was the strongest. Improved medication adherence was associated with reduced caregiver burden for the outcomes of altered work, worry about other people's perceptions of them as a parent, and avoiding social activity, but not family life or worry/stress. There remains an ongoing need to tailor therapies to individual characteristics and ultimately potentially alleviate the burden on daily life experienced by caregivers.

\section{Acknowledgments}

The research was funded by Shire Development, LLC. The study was conducted by ICON Clinical Research, Gaithersburg, MD, USA, in collaboration with Global Perspectives, Berkshire, UK and Survey Sampling International, Shelton, CT, USA. Data presented here were analyzed by Moshe Fridman. Under the direction of the authors, Lisa Tatler PhD and Hannah Wills MBChB, employees of Caudex, Oxford, UK, provided writing assistance for this publication. Editorial assistance in formatting, proofreading, copyediting, and fact checking the manuscript, and in coordinating and collating comments was also provided by Caudex. Shire International $\mathrm{GmbH}$ provided funding to Caudex, Oxford, UK for support in writing, editing, and managing this manuscript. Although employees of Shire were involved in the design, collection, analysis, interpretation, and fact checking of information, the content of this manuscript, interpretation of the data, and the decision to submit the manuscript for publication in Neuropsychiatric Disease and Treatment was made by the authors independently.

The authors thank Valerie Harpin of Ryegate Children's Centre, Sheffield, UK, for her contribution to this study.

\section{Disclosure}

MF is an employee of AMF Consulting and serves as a paid consultant for Shire. TB has served in an advisory or consultancy role for Hexal Pharma, Lilly, Medice, Novartis, Otsuka, Oxford Outcomes (now ICON), PCM Scientific, Shire, and Vifor Pharma. He has received conference attendance support and conference support or speaker's fees from Lilly, Medice, Novartis, and Shire. He is/has been involved in clinical trials conducted by Lilly, Shire, and Vifor Pharma. The present work is unrelated to the above grants and relationships. VS was an employee of, and owned stock/stock options in, Shire at the time of the study. JQ is a speaker or member of an advisory board for FEAADAH, Shire, Eli Lilly, Grünenthal, and Janssen Pharmaceuticals, and has an unrestricted research grant from Otsuka. MHE was an employee of, and owned stock/stock options in, Shire at the time of the study - he is now a freelance consultant. KSC is an employee of, and owns stock/stock options in, Shire. The authors have no other conflicts of interest in this work.

\section{References}

1. NICE. Attention deficit hyperactivity disorder: diagnosis and management. National Clinical Practice Guideline Number 72 (2008; includes 2016 updates). Available from: https://www.nice.org.uk/guidance/cg72. Accessed July 21, 2016.

2. American Psychiatric Association. Diagnostic and Statistical Manual of Mental Disorders, Fifth Edition (DSM-5). Arlington, VA: American Psychiatric Publishing; 2013.

3. Polanczyk G, de Lima MS, Horta BL, Biederman J, Rohde LA. The worldwide prevalence of ADHD: a systematic review and metaregression analysis. Am J Psychiatry. 2007;164(6):942-948.

4. Polanczyk GV, Willcutt EG, Salum GA, Kieling C, Rohde LA. ADHD prevalence estimates across three decades: an updated systematic review and meta-regression analysis. Int J Epidemiol. 2014;43(2):434-442.

5. Polanczyk G, Salum GA, Sugaya LS, Caye A, Rohde LA. Annual Research Review: A meta-analysis of the worldwide prevalence of mental disorders in children and adolescents. J Child Psychol Psychiatry. 2015;56(3):345-365.

6. Taylor E, Dopfner M, Sergeant J, et al. European clinical guidelines for hyperkinetic disorder - first upgrade. Eur Child Adolesc Psychiatry. 2004;13(Suppl 1):I7-I30.

7. Health Ministry of Spain. Guía de Práctica Clínica sobre el Trastorno por Déficit de Atención con Hiperactividad (TDAH) en Niños y Adolescentes. Available from: http://www.guiasalud.es/GPC/ GPC_477_TDAH_AIAQS_compl.pdf. Accessed July 21, 2016.

8. Landelijke Stuurgroep. Multidisciplinaire richtlijn ADHD bij kinderen en jeugdigen Versie 1.0. Available from: http://www.ggzrichtlijnen. nl/index.php?pagina=/richtlijn/item/pagina.php\&richtlijn_id=29. Accessed July 21, 2016.

9. SINPIA. Linee-guida per la diagnosi e la terapia farmacologica del Disturbo da Deficit Attentivo con Iperattività (ADHD) in età evolutiva. Available from: http://www.aidaiassociazione.com/documents/ Linee_guida_SINPIA_Diagnosi.pdf. Accessed July 21, 2016.

10. Deutsche Gesellschaft für Kinder- und Jugendpsychiatrie und Psychotherapie. Hyperkinetische Störungen (F90). Leitlinien zur Diagnostik und Therapie von psychischen Störungen im Säuglings-, Kindes- und Jugendalter. 3. über-arbeitete Auflage ed. German Society for Child and Adolescent Psychiatry and Psychotherapy (DGKJP). Hyperkinetic Disorders (F90). [Guidelines for diagnosis and treatment of mental disorders in infancy, childhood and adolescents. Third edition]. Cologne: Deutsche Ärzte Verlag; 2007. German.

11. Preuss U, Ralston SJ, Baldursson G, et al. Study design, baseline patient characteristics and intervention in a cross-cultural framework: results from the ADORE study. Eur Child Adolesc Psychiatry. 2006; 15(Supp1 1):I4-I14.

12. Ralston SJ, Lorenzo MJ. ADORE - attention-deficit hyperactivity disorder observational research in Europe. Eur Child Adolesc Psychiatry. 2004;13(Suppl 1):I36-I42.

13. Cussen A, Sciberras E, Ukoumunne OC, Efron D. Relationship between symptoms of attention-deficit/hyperactivity disorder and family functioning: a community-based study. Eur J Pediatr. 2012;171(2): 271-280.

14. Davis CC, Claudius M, Palinkas LA, Wong JB, Leslie LK. Putting families in the center: family perspectives on decision making and ADHD and implications for ADHD care. J Atten Disord. 2012;16(8):675-684. 
15. Klassen AF, Miller A, Fine S. Health-related quality of life in children and adolescents who have a diagnosis of attention-deficit/hyperactivity disorder. Pediatrics. 2004;114(5):e541-e547.

16. Strine TW, Lesesne CA, Okoro CA, et al. Emotional and behavioral difficulties and impairments in everyday functioning among children with a history of attention-deficit/hyperactivity disorder. Prev Chronic Dis. 2006;3(2):A52.

17. Kvist AP, Nielsen HS, Simonsen M. The importance of children's ADHD for parents' relationship stability and labor supply. Soc Sci Med. 2013;88:30-38.

18. Sikirica V, Flood E, Dietrich CN, et al. Unmet needs associated with attention-deficit/hyperactivity disorder in eight European countries as reported by caregivers and adolescents: results from qualitative research. Patient. 2015;8(3):269-281.

19. Theule J, Wiener J, Tannock R, Jenkins JM. Parenting stress in families of children with ADHD: a meta-analysis. J Emot Behav Disord. 2013; 21(1):3-17.

20. Biederman J, Munir K, Knee D, et al. High rate of affective disorders in probands with attention deficit disorder and in their relatives: a controlled family study. Am J Psychiatry. 1987;144(3):330-333.

21. Faraone SV, Biederman J, Mennin D, Gershon J, Tsuang MT. A prospective four-year follow-up study of children at risk for ADHD: psychiatric, neuropsychological, and psychosocial outcome. J Am Acad Child Adolesc Psychiatry. 1996;35(11):1449-1459.

22. Bauermeister JJ, Puente A, Martinez JV, Cumba E, Scandar RO, Bauermeister JA. Parent perceived impact of Spaniard boys' and girls' inattention, hyperactivity, and oppositional defiant behaviors on family life. J Atten Disord. 2010;14(3):247-255.

23. Flood E, Gajria K, Sikirica V, et al. The Caregiver Perspective of Paediatric ADHD (CAPPA) survey: understanding sociodemographic and clinical characteristics, treatment use, and impact of ADHD in Europe. $J$ Affect Disord. 2016;200:222-234.

24. Sikirica V, Xie J, Lizhang T, et al. Immediate-release versus extendedrelease guanfacine for treatment of attention-deficit/hyperactivity disorder. Am J Pharm Benefits. 2013;5(4):e85-e94.
25. Agresti A. Analysis of Ordinal Categorical Data. 2nd ed. New York, NY, USA: John Wiley \& Sons; 2010.

26. Peterson B, Harrell FE. Partial proportional odds models for ordinal response variables. Appl Statist. 1990;39(2):205-217.

27. Caci H, Doepfner M, Asherson P, et al. Daily life impairments associated with self-reported childhood/adolescent attention-deficit/ hyperactivity disorder and experiences of diagnosis and treatment: results from the European Lifetime Impairment Survey. Eur Psychiatry. 2014;29(5):316-323.

28. Coghill D, Soutullo C, d'Aubuisson C, et al. Impact of attention-deficit/ hyperactivity disorder on the patient and family: results from a European survey. Child Adolesc Psychiatry Ment Health. 2008;2(1):31.

29. Le HH, Hodgkins P, Postma MJ, et al. Economic impact of childhood/ adolescent ADHD in a European setting: the Netherlands as a reference case. Eur Child Adolesc Psychiatry. 2013;23(7):587-598.

30. Riley AW, Lyman LM, Spiel G, Dopfner M, Lorenzo MJ, Ralston SJ. The Family Strain Index (FSI). Reliability, validity, and factor structure of a brief questionnaire for families of children with ADHD. Eur Child Adolesc Psychiatry. 2006;15 Suppl 1:I72-I78.

31. Tzang RF, Chang YC, Liu SI. The association between children's ADHD subtype and parenting stress and parental symptoms. Int $J$ Psychiatry Clin Pract. 2009;13(4):318-325.

32. Cadman T, Eklund H, Howley D, et al. Caregiver burden as people with autism spectrum disorder and attention-deficit/hyperactivity disorder transition into adolescence and adulthood in the United Kingdom. J Am Acad Child Adolesc Psychiatry. 2012;51(9):879-888.

33. Rockhill C, Violette H, Vander Stoep A, Grover S, Myers K. Caregivers' distress: youth with attention-deficit/hyperactivity disorder and comorbid disorders assessed via telemental health. J Child Adolesc Psychopharmacol. 2013;23(6):379-385.
Neuropsychiatric Disease and Treatment

\section{Publish your work in this journal}

Neuropsychiatric Disease and Treatment is an international, peerreviewed journal of clinical therapeutics and pharmacology focusing on concise rapid reporting of clinical or pre-clinical studies on a range of neuropsychiatric and neurological disorders. This journal is indexed on PubMed Central, the 'PsycINFO' database and CAS,

\section{Dovepress}

and is the official journal of The International Neuropsychiatric Association (INA). The manuscript management system is completely online and includes a very quick and fair peer-review system, which is all easy to use. Visit http://www.dovepress.com/testimonials.php to read real quotes from published authors. 